\title{
Study of Vaccinia and Cowpox viruses' replication in Rac1-N17 dominant-negative cells
}

\author{
Ana Paula Carneiro Salgado ${ }^{1,2}$, Jamária Adriana Pinheiro Soares-Martins ${ }^{1,2,3}$, \\ Luciana Garcia Andrade,2, Jonas Dutra Albarnaz, ${ }^{1,2}$, Paulo César Peregrino Ferreira², \\ Erna Geessien Kroon², Cláudio Antônio Bonjardim,2/+
}

\footnotetext{
${ }^{1}$ Grupo de Transdução de Sinal/Orthopoxvirus e Flavivírus - LABVÍRUS ${ }^{2}$ Laboratório de Vírus, Departamento de Microbiologia, Instituto de Ciências Biológicas, Universidade Federal de Minas Gerais, Belo Horizonte, MG, Brasil

${ }^{3}$ Department of Microbiology and Molecular Genetics, Medical College of Wisconsin, Milwaukee, WI, USA
}

\begin{abstract}
Interfering with cellular signal transduction pathways is a common strategy used by many viruses to create a propitious intracellular environment for an efficient replication. Our group has been studying cellular signalling pathways activated by the orthopoxviruses Vaccinia (VACV) and Cowpox (CPXV) and their significance to viral replication. In the present study our aim was to investigate whether the GTPase Racl was an upstream signal that led to the activation of MEK/ERK1/2, JNK1/2 or Akt pathways upon VACV or CPXV' infections. Therefore, we generated stable murine fibroblasts exhibiting negative dominance to Rac1-N17 to evaluate viral growth and the phosphorylation status of ERK1/2, JNK1/2 and Akt. Our results demonstrated that VACV replication, but not CPXV, was affected in dominant-negative (DN) Rac1-N17 cell lines in which viral yield was reduced in about 10-fold. Viral late gene expression, but not early, was also reduced. Furthermore, our data showed that Akt phosphorylation was diminished upon VACV infection in DN Rac1-N17 cells, suggesting that Rac1 participates in the phosphoinositide-3 kinase pathway leading to the activation of Akt. In conclusion, our results indicate that while Racl indeed plays a role in VACV biology, perhaps another GTPase may be involved in CPXV replication.
\end{abstract}

Key words: Rac1 - Akt - Vaccinia virus - Cowpox virus - virus-host interaction

Vaccinia (VACV) and Cowpox (CPXV) viruses belong to the Poxviridae family, genus Orthopoxvirus. Poxviruses are linear double-stranded DNA viruses that encode more than 200 genes, most of them associated with virus-host interactions and suppression or modulation of host immune response in order to facilitate viral replication. VACV is the prototype of the family and has been vastly studied in the past decades. On the other hand, VACV and CPXV are not only phylogenetically close, but they also share their ability to infect a wide range of hosts, such as humans, cows, rodents and zoo animals. And historically, both VACV and CPXV were involved in the practice of human vaccination against smallpox, a deadly disease caused by Variola virus, which was successfully declared eradicated by the World Health Organization in 1980 (Condit et al. 2006, Moss 2007). Since its eradication, humans stopped being vaccinated and an increasing number of outbreaks

doi: 10.1590/0074-0276108052013004

Financial support: FAPEMIG, CAPES, MCT-Brazil, CNPq

APCS, JDA and LGA were recipients of a predoctoral fellowship from CNPq, LGA was recipient of premaster fellowship from CNPq, CAB, EGK and PCPF are recipients of research fellowships from the CNPq, JAPS-M was recipient of a predoctoral fellowship from CAPES.

+ Corresponding author: claudio.bonjardim@pq.cnpq.br

Received 5 February 2013

Accepted 13 May 2013 in both human and animals caused by poxviruses have been reported in the past years in Brazil, Europe and United States of America (Fonseca et al. 1998, Damaso et al. 2000, Reynolds et al. 2004, Sejvar et al. 2004, Trindade et al. 2007, Vorou et al. 2008, Abrahão et al. 2010, Formenty et al. 2010).

Until this date, it is still intriguing and fascinating how poxviruses and many other viruses have evolved strategies to manipulate host cells by activating, up or down-regulating a variety of cellular signalling pathways to favour a successful infection. For instance, mitogen activated protein kinase (MAPK) cascades are evolutionary conserved enzymes connecting cell-surface receptors to critical regulatory targets within cells leading to responses as diverse as proliferation, differentiation, immune response and cell death (Chang \& Karin 2001, Pearson et al. 2001, Dong et al. 2000, Cargnello \& Roux 2011). The phosphoinositide-3 kinase (PI3K) pathway is another important cell signalling pathway that also regulates a variety of cellular activities including cell growth, proliferation, survival and movement (Hawkins et al. 2006). Therefore, over the years many studies have shown great examples of how viruses manipulate cellular signalling pathways. For instance, activation of the MAPKs MEK/ERK and JNK1/2 is required for productive infection of baculovirus (Katsuma et al. 2007). The MAPK-ERK pathway was also shown to play an important role in regulating gene expression and replication of hepatitis C virus (HCV) (Pei et al. 2012) and Kaposi's sarcoma-associated herpesvirus (Sharma-Walia et al. 2005). Many other studies have reported the activation 
and significance of MAPK JNK pathway for viruses such as influenza (Mehrotra et al. 2007), rotavirus (Holloway \& Coulson 2006) and herpesvirus (Chen et al. 2002, Perkins et al. 2003, Hamza et al. 2004, Zapata et al. 2007). In addition, the role of PI3K/Akt pathway in viral replication has been described for herpesvirus (Qin et al. 2011), flaviviruses (Lee et al. 2005), HCV (He et al. 2002), coxsackievirus B3 (Esfandiarei et al. 2004), influenza (Shin et al. 2007), human immunodeficiency virus type 1 (HIV-1) (Wolf et al. 2001).

In the past decade, our group has shown that VACV and CPXV also stimulate MEK/ERK/1/2/Egr-1 cascade as well as JNK1/2 and PI3K/Akt pathways during infection. Furthermore, our results have demonstrated that these two closely phylogenetic related viruses are able to activate the same signalling pathways upon infection; however, those pathways seem to have a different role in each case. For example, inhibition of MEK/ERK/Egr-1 cascade impairs VACV replication, but has no impact upon CPXV replication (de Magalhães et al. 2001, Andrade et al. 2004, Silva et al. 2006). On the other hand, host survival and viral replication require the activation of the PI3K/Akt pathway after infection for both VACV and CPXV (Soares et al. 2009). Moreover, we have recently demonstrated that JNK $1 / 2$ is abundantly activated at late times during infection and it plays a role in VACV exit and spread (Pereira et al. 2012a, b).

Rho GTPases belong to the Ras superfamily of small GTPases and are also highly conserved throughout eukaryotes with Rho, Racl and Cdc42 being the far best characterised members (Hall 2012). The Rho GTPases function as molecular switches and cycle between an active GTP-bound state and an inactive GDP-bound state. In cells, Rho GTPases exist mainly in their inactive form (Hall 2005, Rossman et al. 2005, Heasman \& Ridley 2008). Activation is mediated by guanine nucleotide exchange factors, while GTPase-activating proteins promote the hydrolysis of GTP to GDP. When bound to GTP, the Rho proteins can activate various downstream effectors, thereby stimulating diverse biological responses, such as actin dynamics, cell cycle progression, cell adhesion, cytoskeletal reorganisation, cellular growth, apoptosis, gene transcription, cell polarity, migration, vesicle trafficking and cytokinesis (Bishop \& Hall 2000, Heasman \& Ridley 2008). Recent studies have showed that Racl GTPase is important for many virus infections such as Herpes simplex virus 1 (Hoppe et al. 2006), HIV-1 (Pontow et al. 2004), hepatitis B virus (HBV) (Coyne et al. 2007), Coxsackievirus (Tan et al. 2008), African swine fever virus (Quetglas et al. 2012) and dengue virus (Zamudio-Meza et al. 2009, Wang et al. 2010). In addition, early and recent studies have shown that VACV activates Rac1 in early times during infection and contributes to viral entry (Locker et al. 2000, Mercer \& Helenius 2008); however, not much is known whether activation of Racl is associated to stimulation of the MAPK ERK and JNK and/or Akt pathways. Evidences for extensive cooperation and cross talk between GTPases and others signalling pathways are well documented in many systems (Denhardt 1996, Teramoto et al. 1996, Fanger et al. 1997, Missy et al. 1998, Hall \& Nobes 2000, Etienne-Mannev- ille \& Hall 2002, Srinivasan et al. 2003, Chamberlain et al. 2004, Jin et al. 2006, Shao et al. 2008, Aksamitiene et al. 2012), including viral infection. For example, Rac1 activation by HBV replication resulted in the phosphorylation of ERK1/2 and Akt (Tan et al. 2008). Rac1 was also found to be an important downstream effector in the entry regulation of Ebola virus. Inhibition of PI3K-AktRacl pathway disrupted normal uptake of virus particles into cells (Saeed et al. 2008) and so on.

Taking these into consideration, the goal of the present work was to examine whether the GTPase Rac1 was a component of the cellular signalling pathways activated during VACV or CPXV' infections. Therefore, we have generated stable murine fibroblasts exhibiting negative dominance for Rac1-N17 in order to evaluate viral growth as well as the phosphorylation status of ERK1/2, JNK1/2 and Akt.

\section{MATERIALS AND METHODS}

Cell culture, antibodies and chemicals - A31 cells (a clone derived from mouse BALB/c 3T3) and Vero cells were cultured in Dulbecco's modified Eagle's medium supplemented with $7.5 \%$ and $5 \%$ heat-inactivated foetal bovine serum (FBS) (Cultilab, Campinas, Brazil), respectively, and antibiotics in $5 \% \mathrm{CO}_{2}$ at $37^{\circ} \mathrm{C}$. The antibodies anti-phospho-JNK/SAPK (Thr183/Tyr185), anti-phosphoERK1/2 (Thr202/Tyr204), anti-phospho-Akt (Ser473), anti-total ERK1/2 and the horse radish peroxidase (HRP) conjugated anti-rabbit and anti-mouse secondary antibodies were purchased from Cell Signaling Technology, Beverly, MA, USA. The anti $\beta$-actin antibody was purchased from Sigma-Aldrich, São Paulo, Brazil. The specific antibodies for the viral $\mathrm{H} 3 \mathrm{~L}$ and SPI-2/CrmA proteins were a generous gift from B Moss (NIAID, Bethesda, MD) and D Pickup (Duke University Medical Center, Durham, NC), respectively. Geneticin (G418) was purchased from Invitrogen, São Paulo, Brazil.

Generation of Racl dominant-negative (DN) (RaclN17) cells - Murine fibroblasts stably displaying DN for the mutant Rac1 (T17N) were generated by transfecting A31 cells with $10 \mu \mathrm{g}$ of either pCDNA3 plasmid carrying Racl insert (Guthrie cDNA Company Resource Center) or with the empty vector (kindly provided by $\mathrm{Dr}$ Oscar Bruña Romero, Federal University of Minas Gerais, Brazil) using standard calcium phosphate protocol (Sambrook et al. 1989). Transfectants were ring cloned after a selection with $800 \mu \mathrm{g} / \mathrm{mL}$ G418 for at least 21 days. Then, the selected clones were expanded and G418 was kept at $200 \mu \mathrm{g} / \mathrm{mL}$. In order to confirm positive G418-resistant clones DNA extractions were performed by phenol-chloroform and the Racl $(\mathrm{T} 17 \mathrm{~N})$ gene fragment was amplified by touchdown polymerase chain reaction (PCR), using the pcDNA3.1 vector primers (T7 forward: 5'-TAATACGACTCACTATAGGG-3' and BGH reverse: 5'-TAGAAGGCACAGTCGAGGC-3'). Amplicons were gel-purified using Wizard $^{\circledR}$ SV Gel and PCR Clean-Up System (Promega), then they were cloned into pGEM-T ${ }^{\circledR}$ Easy Vector Systems (Promega) and transformed in Escherichia coli M15. Colonies were picked to confirm the presence of the DN mutation of 
Rac1 for each G418-resistant A31 clones. Briefly, minipreps were performed by PureYield ${ }^{\mathrm{TM}}$ Plasmid Miniprep System (Promega) and DNA samples were sequenced using the pGEM-T ${ }^{\circledR}$ Easy Vector Systems primer (M13) (Promega) and MegaBACE 1000 capillary sequencer (GE Healthcare, United Kingdom).

Cell growth curves - A31 cells and clones carrying DN Rac1-N17 or empty vector were cultured in 35 $\mathrm{mm}$ dishes at a density of $1 \times 10^{5}$ cells in $7.5 \%$ serum. At the times of $24 \mathrm{~h}, 48 \mathrm{~h}$ and $72 \mathrm{~h}$, cells were washed with room temperature (RT) phosphate-buffered saline (PBS), trypsinised and counted using the Neubauer chamber to calculate cellular growth. Data were confirmed by at least three independent experiments with similar results.

Viruses - For viral stocks, the wild-type VACV (strain WR) and CPXV (strain BR) viruses were propagated in Vero cells. Viruses were then highly purified by sucrose gradient sedimentation as described (Joklik 1962). For viral infections in both A31 and DN Rac1N17 cells lines, cells were counted before seeding them as well as before infection to assure similar number between cell lines. Then, cells were starved by changing the media to $1 \%$ FBS and incubated for $12 \mathrm{~h}$. Cells were infected at the indicated multiplicity of infection (MOI) for the times shown.

Multi-step viral growth curves - Thirty-five millimetres dishes of A31 or DN Rac1-N17 cells lines at a density of $5 \times 10^{5}$ cells were starved with $1 \%$ FBS media for $12 \mathrm{~h}$ and then infected at a MOI of 10 for $3 \mathrm{~h}$, $6 \mathrm{~h}, 12 \mathrm{~h}, 24 \mathrm{~h}, 36 \mathrm{~h}$ and $48 \mathrm{~h}$. After $1 \mathrm{~h}$ adsorption at $37^{\circ} \mathrm{C}$, viral inoculum was aspirated and cells were fed and kept at 1\% FBS media. At each time point, cultures were washed with cold PBS and cells were disrupted by three freezing/thawing cycles. Supernatants were collected and viral yields were quantified by viral plaque assay as described (Campos \& Kroon 1993). Data were confirmed by at least three independent experiments with similar results.

Lysate preparation, electrophoresis and immunoblotting - A31 and DN Rac1-N17 cells were cultured in $60 \mathrm{~mm}$ dishes at the density of $7.5 \times 10^{5}$ and starved for $12 \mathrm{~h}$ followed by infection with either VACV or CPXV at indicated MOI and time. At each time, for whole cell lysates cells were washed with cold PBS and disrupted on ice with lysis buffer $[100 \mathrm{mM}$ Tris- $\mathrm{HCl}(\mathrm{pH} 8.0)$, $1 \%$ Triton X-100, $0.2 \mathrm{mM}$ ethylenediamine tetraacetic acid (EDTA), 20\% glycerol (v/v), 200mM NaCl, $1 \mathrm{mM}$ sodium orthovanadate, $1 \mathrm{mM}$ phenylmethanesulfonyl fluoride (PMSF), $5 \mu \mathrm{g} / \mathrm{mL}$ aprotinin, $2.5 \mu \mathrm{g} / \mathrm{mL}$ leupeptin, 1mM dithiothreitol (DTT)]. Whole cell lysates were collected by centrifugation at 13,500 rpm for 15 $\min$ at $4^{\circ} \mathrm{C}$. For nuclear lysates, cells were scraped from the dish and spun at 3,000 rpm for $3 \mathrm{~min}$ at $4^{\circ} \mathrm{C}$. Then, pellets were ressuspended in hypotonic buffer $(10 \mathrm{mM}$ HEPES $\mathrm{pH} 7.9,10 \mathrm{mM}$ KCL, $0.2 \mathrm{mM}$ EDTA and $1 \mathrm{mM}$ DTT) and incubated on ice for 5 min followed by centrifugation at 2,000 rpm for $2 \mathrm{~min}$. Supernatants were discarded and nuclei pellets were ressuspended in lysis buffer (20mM HEPES pH 7.9, 0.42M NaCl, 2mM EDTA and $1 \mathrm{mM}$ DTT, $1 \mathrm{mM}$ PMSF, $5 \mu \mathrm{g} / \mathrm{mL}$ aprotinin, $2.5 \mu \mathrm{g} /$ $\mathrm{mL}$ leupeptin) and incubated on ice for $30 \mathrm{~min}$. Finally, samples were centrifuged at $12,000 \mathrm{rpm}$ for $15 \mathrm{~min}$ at $4^{\circ} \mathrm{C}$ and supernatants were saved and stored at $-70^{\circ} \mathrm{C}$. Protein concentration was determined by the Bio-Rad assay (Bio-Rad Laboratories, USA). Fifteen (nuclear cell lysates) to $30 \mu \mathrm{g}$ (whole cell lysates) of protein per sample were separated by electrophoresis on a $10 \%$ sodium dodecyl sulphate polyacrylamide gel and transferred to nitrocellulose membranes as previously described (de Magalhães et al. 2001). Briefly, membranes were blocked at RT for $1 \mathrm{~h}$ with PBS containing $0.1 \%$ Tween-20 and $5 \%(\mathrm{w} / \mathrm{v})$ non-fat milk. The membranes were washed three times with PBS containing $0.1 \%$ Tween-20, incubated with specific polyclonal or monoclonal antibody (1:1,000-1:3,000) in PBS containing 0.1\% Tween-20 and $5 \%(\mathrm{w} / \mathrm{v})$ bovine serum albumin, followed by incubation with the HRP-conjugated secondary anti-rabbit or antimouse antibody $\mathrm{Ab}$. Immunoreactive bands were visualised by the ECL Detection System as described in the manufacturer's instructions (GE Healthcare, UK).

Virus plaque phenotype - A31 and DN Rac1-N17 cells were cultured in $35 \mathrm{~mm}$ dishes, starved and infected with either VACV or CPXV at 100 plaque forming units/dish. After $1 \mathrm{~h}$ adsorption at $37^{\circ} \mathrm{C}$, inoculum was aspirated and cells were fed with semi-solid medium containing $0.5 \%$ agarose. After $48 \mathrm{~h}$ cells were fixed and stained with $10 \%$ formaldehyde $/ 0.3 \%$ (wt/vol) crystal violet solution.

\section{RESULTS}

Cell growth evaluation of murine fibroblasts displaying DN for Rac1-N17 - To uncover whether Racl GTPase is part of the signalling pathways activated by VACV and CPXV infections we have generated stable murine fibroblasts that displays a DN form of Rac1 (DN Racl); there is a mutation on the threonine residue (position 17) to asparagine, which unable its phosphorylation and function. Therefore, we first performed cellular growth curves of A31 cells and DN Rac1-N17 cell lines (clones 3 and 6). As shown in Fig. 1, our results demonstrate that the DN of Racl did not affect cellular growth; either clone 3 (dark grey bars) or 6 (black bars) grew at similar levels as A31 cells (white bars) or cells carrying the empty vector (light grey bars).

$V A C V$ replication, but not $C P X V$, is compromised in DN cells for Racl-N17 - Our next step was to investigate the impact of the DN of Rac1-N17 upon VACV and CPXV' replication. In order to do that, we performed viral growth curves and measured virus production. Our results show that viral yield was greatly reduced for VACV in about $1 \log$ (Fig. 2A) when compared to A31 cells, while CPXV had comparable yield in both cells lines (Fig. 2B). Experiments were also performed in cells carrying the empty vector and viral yield for both VACV and CPXV were also similar to A31 cells (data not shown). Furthermore, we examined VACV and CPXV plaque phenotype; as shown in Fig. $2 \mathrm{C}$, the plaque size 
for VACV was considerably smaller (top circles) in the DN Rac1-N17 cells, whereas for CPXV no major changes in the plaque size were observed when compared to A31 cells (bottom circles). These results suggest that Rac1 may not play an important role for CPXV biology as it is indicative for VACV.

Analysis of viral gene expression in DN Racl-N17 cells - Bearing in mind that we observed a decrease in VACV production, further analyses were performed to investigate if viral early and late gene expression were compromised as well. For that, A31 or DN Rac1-N17 cells were left uninfected (MOCK) or infected with VACV (MOI of 10) and harvested from 3-36 h post-infection (hpi), followed by western blot analyses for either the early viral protein SPI-2 or the late viral protein H3. Our results demonstrate that viral early gene expression displayed comparable levels between A31 and DN Rac1-N17 cells (Fig. $3 \mathrm{~A}, \mathrm{D}$, respectively). On the other hand, viral late gene expression was delayed in the DN Rac1-N17 cells comparing to A31 cells (Fig. 3E, B, Lanes 3-7, respectively). As expected, no difference in viral gene expression was observed in cells carrying the empty vector when compared to A31 cells (data not shown). Infections with CPXV were also made in parallel and early and late viral gene expression exhibited equivalent levels in A31 and DN Rac1-N17 cells (data not shown) (Fig. 3G, I, Lanes 3-7).

Phosphorylation of ERK1/2 is Racl-independent during $V A C V$ infection - We have shown that VACV infection can promote the phosphorylation of MAPK ERK1/2; a sustained activation was observed starting at 5 min post-infection (de Magalhães et al. 2001) until 8 hpi (Andrade et al. 2004). Intending to better characterise the components of the signalling pathways activated by VACV infection, we evaluated whether ERK1/2 phosphorylation status was affected by the DN of Rac1N17. For this purpose, A31 or DN Racl-N17 cells were infected with VACV (MOI of 10) and harvested at $4 \mathrm{hpi}$ for immunoblot analysis. As shown in Fig. 4, phosphorylation of ERK1/2 presented similar levels in A31 cells

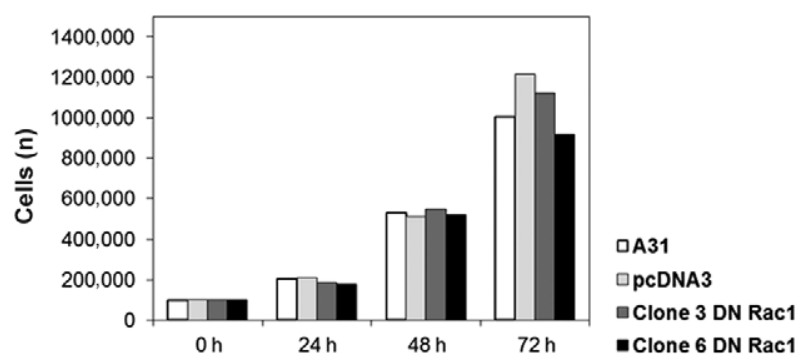

Fig. 1: murine fibroblasts displaying negative dominance for Rac1N17 grow at similar levels as the wild-type cells. A31 wild-type cells (white bars), dominant-negative (DN) Rac1-N17 cells (clones 3 or 6, dark grey and black bars, respectively) and cells carrying an empty vector pcDNA3 (light grey bars) were cultured in $35 \mathrm{~mm}$ dishes starting at $1 \times 10^{5}$ cells in $7.5 \%$ serum. At the times of $24 \mathrm{~h}, 48 \mathrm{~h}$ and 72 h cells were counted using a Neubauer chamber to calculate cellular growth. At least three independent experiments were performed with similar results, but the most representative curve is shown. and DN Rac1-N17 (clones 3 and 6) (compare Lanes 2, 4 and 6). Our data indicate that ERK1/2 activation upon VACV infection is independent of Racl.

Akt phosphorylation is reduced in DN Racl-N17 cells upon VACV infection - Our previous studies have also shown that VACV activates the PI3K/Akt signal-
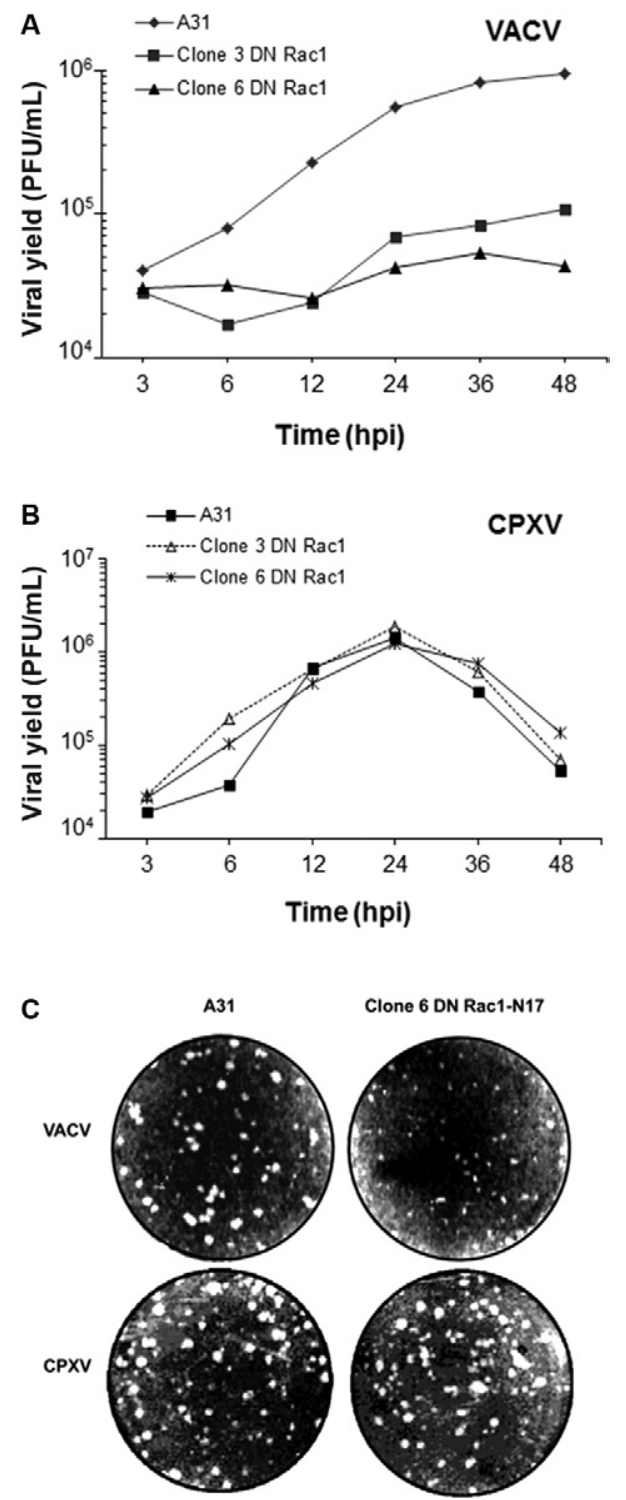

Fig. 2: Vaccinia virus (VACV) but not Cowpox virus (CPXV) replication is impaired in Rac1-N17 dominant-negative (DN) cells. Viral growths were evaluated in either A31 wild-type cells or DN Rac1-N17 (clones 3 or 6 ). Cells were serum starved for $12 \mathrm{~h}$ prior infection with either VACV (A) or CPXV (B) at a multiplicity of infection of 10; at the time points of $3 \mathrm{~h}$ post-infection (hpi), $6 \mathrm{hpi}, 12 \mathrm{hpi}, 24 \mathrm{hpi}, 36 \mathrm{hpi}$ and 48 hpi cells were harvested to measure viral yields. At least three independent experiments were performed with similar results (C). Plaque phenotype of VACV (top) or CPXV (bottom) in either A31or DN Rac1-N17 cells. Confluent cell monolayers were serum starved for $12 \mathrm{~h}$ followed by infection with VACV or CPXV at 100 plaque forming units (PFU). Cells were stained with 10\% formaldehyde $/ 0.3 \%$ crystal violet solution at $48 \mathrm{hpi}$. 
ling pathway in early and late times during infection and when this cascade is inhibited, viral yield is dramatically reduced (Soares et al. 2009). Here we evaluated whether Racl would participate in this signalling pathway. To address that, A31 or DN Rac1-N17 cells were left uninfected (MOCK) or infected with VACV, MOI of 10; cells were harvested at $30 \mathrm{~min}, 1 \mathrm{hpi}, 3 \mathrm{hpi}, 24 \mathrm{hpi}$ and $30 \mathrm{hpi}$, in which cell lysates were collected and subjected to immunoblot analysis. Our results demonstrate that Akt phosphorylation was greatly delayed, particularly at early times during infection (Fig. 5A, B, Lanes 3-7). In contrast, DN of Rac1-N17 upon CPXV infection did not affect Akt phosphorylation (Fig. 5C, D, Lanes 2-4).

Examination of JNK1/2 activation during VACV and $C P X V$ infection - GTP-binding proteins controlling the enzymatic activity of MAPKs such as JNK has been described (Seger \& Krebs 1995, Teramoto et al. 1996).

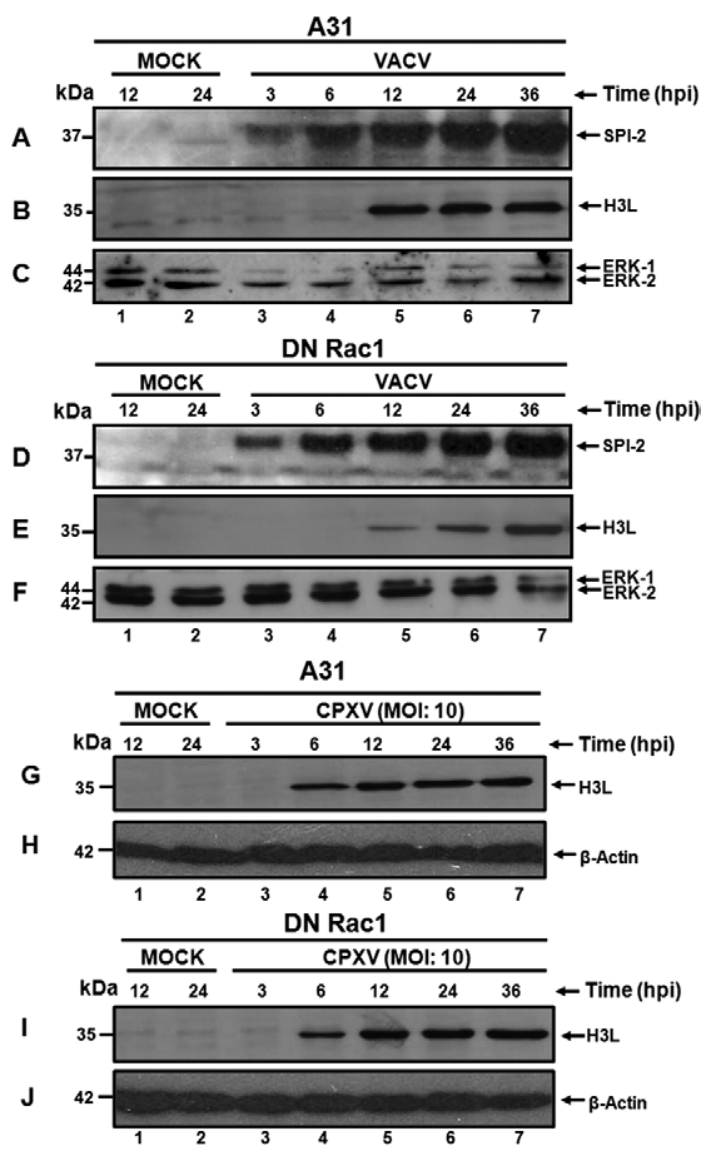

Fig. 3: analysis of viral gene expression in A31 Rac1-N17 dominantnegative (DN) cells upon Vaccinia virus (VACV) and Cowpox virus (CPXV) infection. A31 (A-C, G, H) and DN Rac1-N17 (D-F, I, J) cells were serum starved for $12 \mathrm{~h}$ prior infection with VACV or CPXV at a multiplicity of infection (MOI) of 10. At the various time points shown, cell lysates were harvested and analysed by Western blotting using antibodies raised against the viral proteins CrmA (SPI-2) (A, D) or H3L (B, E, G, I). Anti-total ERK1/2 antibody (C, F) or anti- $\beta$-actin antibody $(\mathrm{H}, \mathrm{J})$ were used as internal controls for protein loading. Molecular masses (in $\mathrm{kDa}$ ) are indicated on the left. hpi: hours postinfection.
Recently, we have demonstrated that VACV induces JNK1/2 activation, mostly at late times during infection, with a role in viral exit and spread (Pereira et al. 2012a, b). Therefore, we decided to investigate whether phosphorylation of JNK was affected by the DN of Rac1-N17. For that, A31 or DN Rac1-N17 cells were left uninfected (MOCK) or infected with VACV (MOI of 10) from 3-42 h. At each time, cells were harvested and cell lysates were used for western blot analysis using specific anti-phospho JNK1/2 antibody. As shown in Fig. 6A, VACV infection leads to activation of JNK1/2 during its whole life cycle, with a robust increase in the levels of JNK1/2 phosphorylation from 12-42 hpi (Lanes $3-8)$. On the other hand, our results show a noteworthy difference in JNK1/2 pattern of phosphorylation when we compare VACV-infected DN Racl-N17 to wild-type A31 cells; phosphorylation of JNK1/2 can be detected at early times as 3 hpi in A31 cells while similar levels are detected only from 24 hpi in DN Rac1-N17 cells (Fig. 6A, C, Lanes 3-8). Unlike VACV, infection with CPXV presented equal levels of JNK phosphorylation in DN Rac1-N17 and A31 cells (Fig. 6E, Lanes 2, 4, 6).

\section{DISCUSSION}

The interaction of viruses with cell surface receptors can elicit two types of signals, conformational changes of viral particles and intracellular signals triggering specific cellular reactions, such as the immune response. As a result, many viruses have evolved strategies to counteract cellular signalling pathways to efficiently produce viral progeny (Greber 2002).

We have shown previously that the orthopoxviruses VACV and CPXV, which are phylogenetically close, activate the same signalling cascades such as MEK1/2/ ERK1/2/Egr-1; however, while the stimulation of this pathway is beneficial for VACV replication, the biological significance for CPXV life cycle is still not elucidated (Andrade et al. 2004, Silva et al. 2006). In contrast, blocking of PI3K/Akt cascade reduced dramatically viral yield for both viruses (Soares et al. 2009).

The GTPase Racl is a component of the cellular signalling pathways that is activated at early times (up to 1 h) during VACV infection, playing a role in viral entry

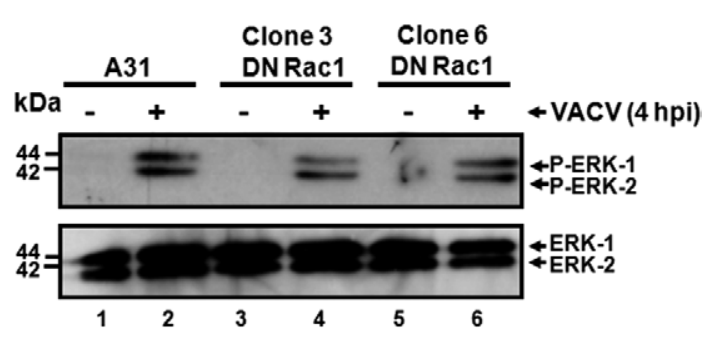

Fig. 4: ERK1/2 activation by Vaccinia virus (VACV) infection is Rac1independent. A31 and dominant-negative (DN) Rac1-N17 cells were serum starved for $12 \mathrm{~h}$ and then infected with VACV at a multiplicity of infection of 10. At $4 \mathrm{~h}$ post-infection (hpi), cell lysates were collected and the phosphorylation status of ERK1/2 was analysed by Western blotting. Anti-total ERK1/2 antibody was used as an internal control for protein loading. Molecular masses (in $\mathrm{kDa}$ ) are indicated on the left. 
by acting upstream of PAK1 (Locker et al. 2000, Mercer \& Helenius 2008); however, it is unknown whether Rac1 participates in the previously characterised signalling pathways stimulated upon VACV and CPXV' infection. Therefore, in the present work we investigated the impact of the DN of Rac1-N17 during viral replication.

Our results demonstrated, as expected, that the DN of Rac1-N17 did not affect cell growth when compared to both parental A31 cells and cells carrying the empty vector. On the other hand, we demonstrated that only VACV replication was impaired by the DN of Rac1-N17, resulting in viral plaques with reduced sizes, whereas for CPXV, no major differences were observed. This was further confirmed when viral protein accumulation was analysed. Only late protein accumulation, exemplified by $\mathrm{H} 3 \mathrm{~L}$, was greatly inhibited only during VACV infection of Rac1-N17 DN cells, corroborating the defect found in VACV progeny production in those cells. These findings indicated that Racl GTPase plays a role during VACV infection, but the same is not valid for CPXV infection, at least in regard to progeny generation and dissemination.

We also provide evidence that Racl is not a component of the MEK1/2/ERK1/2 pathway during VACV infection. However, our data indicates that Racl participates in the signalling pathway of PI3K leading to the activation of Akt, but it is unclear whether Racl is upstream or downstream of PI3K. In both situations, Akt is a key signalling switch downstream from both PI3K and Rac1. Many studies have shown PI3K as an upstream regulator of Racl in systems others than viral infection (Innocenti et al. 2003, Mertens et al. 2003, Wang et al.

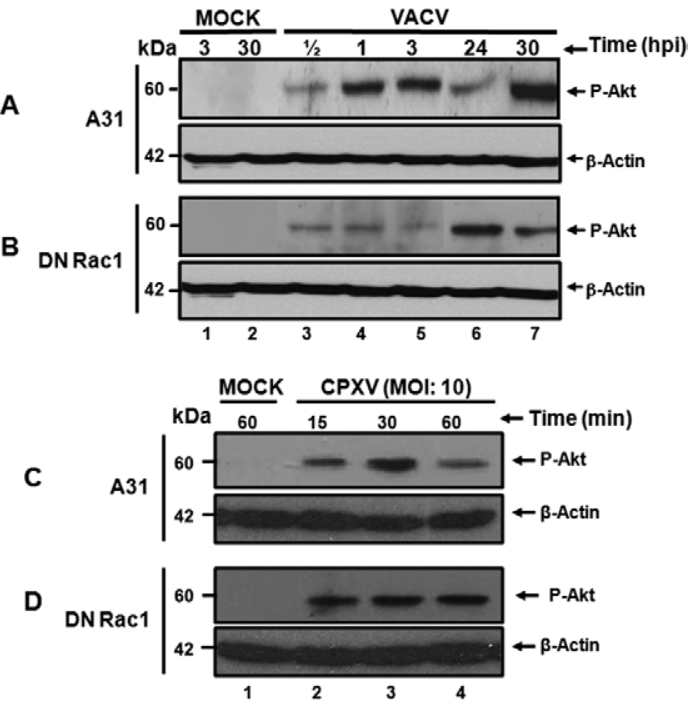

Fig. 5: Akt phosphorylation is affected in A31 Rac1-N17 dominantnegative (DN) cells only upon Vaccinia virus (VACV) infection. A31 (A, C) and DN Rac1-N17 (B, D) cells were serum starved for $12 \mathrm{~h}$ prior infection with VACV or Cowpox virus (CPXV) at a multiplicity of infection (MOI) of 10. At the various time points shown, cell lysates were collected and the phosphorylation status of Akt was analysed by Western blotting. Anti- $\beta$-actin antibody was used as an internal control for protein loading. Molecular masses (in $\mathrm{kDa}$ ) are indicated on the left. hpi: hours post-infection.
2006, Gündüz et al. 2010), but the opposite has also been reported (Harokopakis et al. 2006, Lin et al. 2011).

Previously, we have demonstrated that inhibition of PI3K by its highly selective inhibitor LY294002 abolishes Akt phosphorylation upon either VACV or CPXV infections (Soares et al. 2009) and few hpi cells undergo apoptosis. In the present work, we did not observe any morphological signs of cell death or apoptosis in cells displaying DN for Rac1-N17. For that reason, our results suggest that the minimum levels of Akt phosphorylation detected in infected DN Rac1-N17 cells at early times may be enough to trigger survival signals to keep cells alive for few hours while virus replicates, although they may be not sufficient to generate an appropriate environment for a successful virus production.

We also find that Rac1 is a component of the JNK1/2 pathway during VACV infection, but the same was not observed for CPXV. We recently documented that VACV replication is not affected when infection takes place in JNK1/2-deficient murine fibroblasts; however, viral exit and spread is deregulated leading to viral plaques of augmented size and to an increase in the formation and release of cell-associated enveloped virus and extracellular enveloped virus (Pereira et al. 2012b). Since VACV late protein accumulation and progeny formation were impaired in Rac1-N17 DN cells, we concluded that Racl role takes place earlier than the progeny exit step. We also concluded that the defects in VACV replication in Rac1-N17 DN cells are associated to the reduced Akt

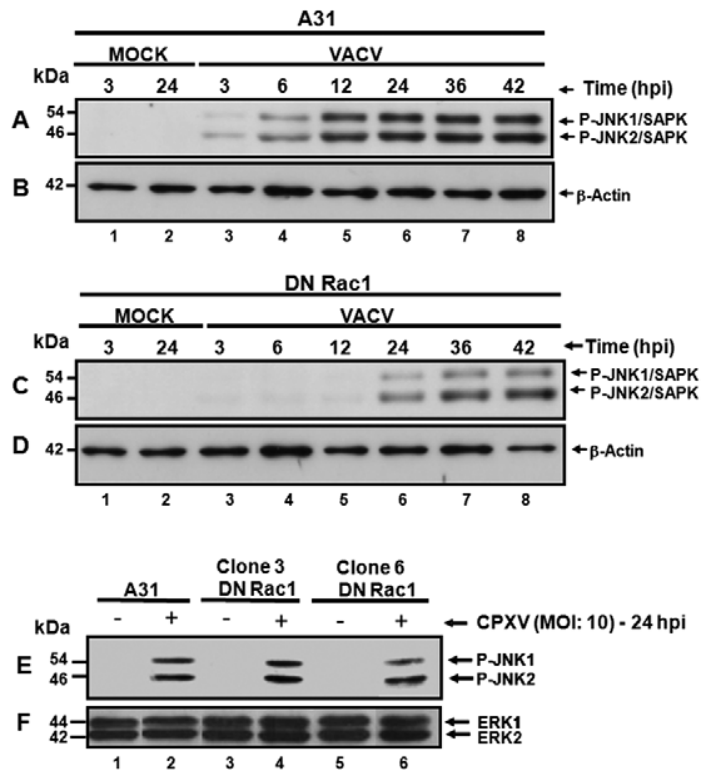

Fig. 6: examination of JNK1/2 activation during Vaccinia virus (VACV) and Cowpox virus (CPXV) infection. A31 and dominantnegative (DN) Rac1-N17 cells were serum starved for $12 \mathrm{~h}$ and then infected with VACV or CPXV at a multiplicity of infection (MOI) of 10. At the various time points indicated (for VACV) or $12 \mathrm{~h}$ postinfection (hpi) (for CPXV), cell lysates were collected to investigate JNK1/2 phosphorylation status (A, C, E) by Western blotting. Anti- $\beta$ actin antibody was used as an internal control for protein loading (B, $\mathrm{D}, \mathrm{F}$ ). Molecular masses (in $\mathrm{kDa}$ ) are indicated on the left. 
activation early in infection rather than to Racl participation in JNK1/2 signalling pathway.

Initial and recent studies have demonstrated that Rac1 is activated at early times during VACV infection and it plays a role in viral entry. Furthermore, staurosporine (non-specific inhibitor of protein kinases), genistein (tyrosine kinases inhibitor), wortmannin (PI3K inhibitor) and EIPA (selective inhibitor of $\mathrm{Na}+/ \mathrm{H}+$ exchange) prevented Racl activation upon VACV infection; however, when cells were transfected with a constitutive active form of Racl viral entry was restored only in the presence of staurosporine and genistein, but not wortmannin or EIPA. These results suggest that activation of Racl itself is not enough to guarantee viral entry, but it contributes to it (Locker et al. 2000, Mercer \& Helenius 2008). Our results indicate that reduction of viral yield during VACV infection may be not related to the total impairment of viral entry since we were able to detect early gene expression at the same levels in A31 and DN Rac1-N17 cell lines.

In summary, our studies revealed that the small GTPase Racl plays an important role during VACV replication by participating in the signalling pathway of PI3K/Akt, which may contribute to cell survival and consequently to a productive viral infection; however, this feature cannot be extended to CPXV. Therefore, further investigations are required to address if CPXV activates another GTPase and its participation in cellular signalling pathways activated upon infection as well as viral entry. By uncovering the components that participate in the cellular signalling pathways activated by those two phylogenetically close orthopoxviruses, a better understanding about the relevance of these events for viral life cycle will be established.

\section{ACKNOWLEDGEMENTS}

We are grateful to Angela S Lopes, Hilda MV Gama and João R dos Santos, for their secretarial and technical assistance. We also thank HA Armelin and MC Sogayar, Department of Biochemistry, University of São Paulo, São Paulo, Brazil, who kindly provided us with the A31 cell line. VACV (strain WR) and CPXV (strain BR) were obtained from C Jungwirth, Universität Würzburg, Würzburg, Germany.

\section{REFERENCES}

Abrahão JS, Silva-Fernandes AT, Lima LS, Campos RK, Guedes MI, Cota MM, Assis FL, Borges IA, Souza-Júnior MF, Lobato ZI, Bonjardim CA, Ferreira PC, Trindade GS, Kroon EG 2010. Vaccinia virus infection in monkeys, Brazilian Amazon. Emerg Infect Dis 16: 976-979.

Aksamitiene E, Kiyatkin A, Kholodenko BN 2012. Cross-talk between mitogenic Ras/MAPK and survival PI3K/Akt pathways: a fine balance. Biochem Soc Trans 40: 139-146.

Andrade AA, Silva PN, Pereira AC, de Sousa LP, Ferreira PC, Gazzinelli RT, Kroon EG, Ropert C, Bonjardim CA 2004. The vaccinia virus-stimulated mitogen-activated protein kinase (MAPK) pathway is required for virus multiplication. Biochem J 381: 437-446.

Bishop A, Hall A 2000. Rho GTPases and their effector proteins. Biochem J 348: 241-255.

Campos MAS, Kroon EG 1993. Critical period for irreversible block of vaccinia virus replication. Rev Microbiol 24: 104-110.
Cargnello M, Roux PP 2011. Activation and function of the MAPKs and their substrates, the MAPK-activated protein kinases. Microbiol Mol Biol Rev 75: 50-83.

Chamberlain MD, Berry TR, Pastor MC, Anderson DH 2004. The p85-subunit of phosphatidylinositol 3-kinase binds to and stimulates the GTPase activity of Rab proteins. $J$ Biol Chem 279: 48607-48614.

Chang L, Karin M 2001. Mammalian MAP kinase signaling cascades. Nature 410: 37-40.

Chen SY, Lu J, Shih YC, Tsai CH 2002. Epstein-Barr virus latent membrane protein $2 \mathrm{~A}$ regulates c-Jun protein through extracellular signal-regulated kinase. J Virol 76: 9556-9561.

Condit RC, Moussatche N, Traktman P 2006. In a nutshell: structure and assembly of the vaccinia virion. Adv Virus Res 66: 31-124.

Coyne CB, Shen L, Turner JR, Bergelson JM 2007. Coxsackievirus entry across epithelial tight junctions requires occluding and the small GTPases Rab34 and Rab5. Cell Host Microbe 2: 181-192.

Damaso CR, Esposito JJ, Condit RC, Moussatche N 2000. An emergent poxvirus from humans and cattle in Rio de Janeiro state: Cantagalo virus may derive from Brazilian smallpox vaccine. Virology 277: 439-449.

de Magalhães JC, Andrade AA, Silva PN, Sousa LP, Ropert C, Ferreira PC, Kroon EG, Gazzinelli RT, Bonjardim CA 2001. A mitogenic signal triggered at an early stage of vaccinia virus infection: implication of MEK/ERK and protein kinase $A$ in virus multiplication. J Biol Chem 276: 38353-38360.

Denhardt DT 1996. Signal-transducing protein phosphorylation cascades mediated by Ras/Rho proteins in the mammalian cell: the potential for multiplex signal. Biochem J 318: 729-747.

Dong C, Yang DD, Tournier C, Whitmarsh, AJ, Xu J, Davis RJ, Flavell RA 2000. JNK is required for effector T-cell function but not for T-cell activation. Nature 405: 91-94.

Esfandiarei M, Luo H, Yanagawa B, Suarez A, Debiri D, Zhang J, McManus BM 2004. Protein kinase B/Akt regulates coxsackievirus $\mathrm{B} 3$ replication through a mechanism which is not caspase dependent. J Virol 78: 4289-4298.

Etienne-Manneville S, Hall A 2002. Rho GTPases in cell biology. Nature 420: 629-635.

Fanger GR, Johnson NL, Johnson GL 1997. MEK kinases are regulated by EGF and selectively interact with $\mathrm{Rac} / \mathrm{Cdc} 42$. EMBO J 16: 4961-4972.

Fonseca FG, Lanna MC, Campos MA, Kitajima EW, Peres JN, Golgher RR, Ferreira PC, Kroon EG 1998. Morphological and molecular characterization of the poxvirus BeAn 58058. Arch Virol 143: 1171-1186.

Formenty P, Muntasir MO, Damon I, Chowdhary V, Opoka ML, Monimart C, Mutasim EM, Manuguerra JC, Davidson WB, Karem KL, Cabeza J, Wang S, Malik MR, Durand T, Khalid A, Rioton T, Kuong-Ruay A, Babiker AA, Karsani ME, Abdalla MS 2010. Human monkeypox outbreak caused by novel virus belonging to Congo Basin clade, Sudan 2005. Emerg Infect Dis 16: $1539-1545$.

Greber UF 2002. Signalling in viral entry. Cell Mol Life Sci 59: 608-626.

Gündüz D, Thom J, Hussain I, Lopez D, Härtel FV, Erdogan A, Grebe M, Sedding D, Piper HM, Tillmanns H, Noll T, Aslam M 2010. Insulin stabilizes microvascular endothelial barrier function via phosphatidylinositol 3-kinase/akt-mediated Racl activation. Arterioscler Thromb Vasc Biol 30: 1237-1245.

Hall A 2005. Rho GTPases and the control of cell behavior. Biochem Soc Trans 33: 891-895. 
Hall A 2012. Rho family GTPases. Biochem Soc Trans 40: 1378-1382.

Hall A, Nobes CD 2000. Rho GTPases: molecular switches the control the organization and dynamics of the actin cytoskeleton. Phil Trans R Soc Lond 355: 965-970.

Hamza MS, Reyes RA, Izumiya Y, Wisdom R, Hung HJ, Luciw PA 2004. ORF36 protein kinase of Kaposi's sarcoma herpesvirus activates the c-Jun $\mathrm{N}$-terminal kinase signaling pathway. $J$ Biol Chem 279: 38325-38330.

Harokopakis E, Albzreh MH, Martin MH, Hajishengallis G 2006. TLR2 transmodulates monocyte adhesion and transmigration via Rac1- and PI3K- mediated inside-out signaling in response to Porphyromonas gingivalis fimbriae. J Immunol 176: 7645-7656.

Hawkins PT, Anderson KE, Davidson K, Stephens LR 2006. Signalling through cClass I PI3Ks in mammalian cells. Biochem Soc Trans 34: 647-662.

He Y, Nakao H, Tan SL, Polyak SJ, Neddermann P, Vijaysri S, Jacobs BL, Katze MG 2002. Subversion of the cell signaling pathways by hepatitis $\mathrm{C}$ virus nonstructural $5 \mathrm{~A}$ protein via interaction with $\mathrm{Grb} 2$ and P85 phosphatidylinositol 3-kinase. J Virol 76: 9207-9217.

Heasman SJ, Ridley AJ 2008. Mammalian Rho GTPases: new insights into their functions from in vivo studies. Nat Rev Mol Cell Biol 9: 690-701.

Holloway G, Coulson B 2006. Rotavirus activates JNK and p38 signaling pathways in intestinal cells, leading to AP-1-driven transcriptional responses and enhanced virus replication. $J$ Virol 80 : 10624-10633.

Hoppe S, Schelhaas M, Jaeger V, Liebig T, Petermann P, KnebelMorsdorf D 2006. Early herpes simplex virus type 1 infection is dependent on regulated $\mathrm{Rac1} / \mathrm{Cdc} 42$ signalling in epithelial MDCKII cells. J Gen Virol 87: 3483-3494.

Innocenti M, Frittoli E, Ponzanelli I, Falck JR, Brachmann SM, Di Fiore PP, Scita G 2003. Phosphoinositide 3-kinase activates Rac by entering in a complex with Eps8, Abi1 and Sos-1. J Cell Biol 160:17-23.

Jin S, Ray RM, Johnson LR 2006. Rac1 mediates intestinal epithelial cell apoptosis via JNK. Am J Physiol Gastrointest Liver Physiol 291: G1137-G1147.

Joklik WK 1962. The purification of four strains of poxvirus. Virology 18: 9-18.

Katsuma S, Mita K, Shimadai T 2007. ERK and JNK-dependent signaling pathways contribute to Bombyx mori nucleopolyhedrovirus infection. J Virol 81: 13700-13709.

Lee CJ, Liao CL, Lin YL 2005. Flavivirus activates phosphatidylinositol 3-kinase signaling to block caspase-dependent apoptotic cell death at the early stage of virus infection. J Virol 79: 8388-8399.

Lin $\mathrm{CH}$, Cheng HW, Ma HP, Wu CH, Hong CY, Chen BC 2011. Thrombin induces NF-kB activation and IL-8/CXCL8 expression in lung epithelial cells by a Rac1-dependent PI3K/Akt Pathway. $J$ Biol Chem 286: 10483-10494.

Locker JK, Kuehn A, Schleich S, Rutter G, Hohenberg H, Wepf R, Griffiths G 2000. Entry of the two infectious forms of vaccinia virus at the plasma membrane is signaling-dependent for the IMV but not the EEV. Mol Biol Cell: 2497-2511.

Mehrotra S, Chhabra A, Hegde U, Chakraborty NG, Mukherji B 2007. Inhibition of c-Jun N-terminal kinase rescues influenza epitopospecific human cytolytic T lymphocytes from activation-induced cell death. J Leukoc Biol 81: 539-547.

Mercer J, Helenius A 2008. Vaccinia virus uses macropinocytosis and apoptotic mimicry to enter host cells. Science 320: 531-535.
Mertens AE, Roovers RC, Collard JG 2003. Regulation of Tiam1-Rac signaling. FEBS Lett 546: 11-16.

Missy K, Poucke VV, Raynal P, Viala C, Mauco G, Plantavid M, Chap H, Payrastre B 1998. Lipid products of phosphoinositide 3-kinase interact with Rac1 GTPase and stimulate GDP dissociation. J Biol Chem 273: 30279-30286.

Moss B 2007. Poxviridae. In BN Fields, Knipe DM, Howley PM (ed.), Virology, Vol. 2, 5th ed., Lippincott-Raven, Philadelphia, p. 2905-2946.

Pearson G, Robinson F, Gibson TB, Xu BE, Karandikar M, Berman K, Cobb MH 2001. Mitogen-activated protein (MAP) kinase pathways: regulation and physiological functions. Endocr Rev 22: 153-183.

Pei R, Zhang X, Xu S, Meng Z, Roggendorf M, Lu M, Chen X 2012. Regulation of hepatitis $\mathrm{C}$ virus replication and gene expression by the MAPK-ERK pathway. Virol Sin 27: 278-285.

Pereira AC, Leite FG, Brasil BS, Soares-Martins JA, Torres AA, Pimenta PF, Souto-Padrón T, Traktman P, Ferreira PC, Kroon EG, Bonjardim CA 2012a. A vaccinia virus-driven interplay between the MKK4/7-JNK1/2 pathway and cytoskeleton reorganization. $J$ Virol 86: 172-184.

Pereira AC, Soares-Martins JA, Leite FG, da Cruz AF, Torres AA, Souto-Padrón T, Kroon EG, Ferreira PC, Bonjardim CA 2012b. SP600125 inhibits orthopoxviruses replication in a JNK1/2-independent manner: implication as a potential antipoxviral. Antiviral Res 93: 69-77.

Perkins D, Gyure KA, Pereira EF, Aurelian L 2003. Herpes simplex virus type 1-induced encephalitis has an apoptotic component associated with activation of c-Jun N-terminal kinase. J Neurovirol 9: 101-111.

Pontow SE, Heyden NV, Wei S, Ratneri L 2004. Actin cytoskeletal reorganizations and coreceptor-mediated activation of Rac during human immunodeficiency virus-induced cell fusion. $J$ Virol 78: 7138-7147.

Qin D, Feng N, Fan W, Ma X, Yan Q, Lv Z, Zeng Y, Zhu J, Lu C 2011. Activation of PI3K/AKT and ERK MAPK signal pathways is required for the induction of lytic cycle replication of Kaposi's sarcoma-associated herpesvirus by herpes simplex virus type 1 . BMC Microbiol 11: 240.

Quetglas JI, Hernáez B, Galindo I, Muñoz-Moreno R, Cuesta-Geijo MA, Alonso C 2012. Small Rho GTPases and cholesterol biosynthetic pathway intermediates in African swine fever virus infection. J Virol 86: 1758-1767.

Reynolds MG, Cono J, Curns A, Holman RC, Likos A, Regnery R, Treadwell T, Damon I 2004. Human monkeypox. Lancet Infect Dis 4: 604-605.

Rossman KL, Der CJ, Sondek J 2005. GEF means go: turning on RHO GTPases with guanine nucleotide-exchange factors. Nat Rev Mol Cell Biol 6: 167-180.

Saeed MF, Kolokoltsov AA, Freiberg AN, Holbrook MR, Davey RA 2008. Phosphoinositide-3 kinase-Akt pathway controls cellular entry of Ebola virus. PLoS Pathog 4:1-11.

Sambrook J, Fritschi EF, Maniatis T 1989. Molecular cloning: a laboratory manual, Cold Spring Harbor Laboratory Press, New York, $745 \mathrm{pp}$.

Seger R, Krebs EG 1995. The MAPK signaling cascade. FASEB J 9: 726-735.

Sejvar JJ, Chowdary Y, Schomogyi M, Stevens J, Patel J, Karem K, Fischer M, Kuehnert MJ, Zaki SR, Paddock CD, Guarner J, Shieh WJ, Patton JL, Bernard N, Li Y, Olson VA, Kline RL, Loparev VN, Schmid DS, Beard B, Regnery RR, Damon IK 2004. Human 
monkeypox infection: a family cluster in the midwestern United States. J Infect Dis 190: 1833-1840.

Shao H, Yi XM, Wells A 2008. Epidermal growth factor protects fibroblasts from apoptosis via PI3 kinase and Rac signaling pathways. Wound Repair Regen 16: 551-558.

Sharma-Walia N, Krishnam HH, Naranatt PP, Zeng L, Smith MS, Chandran B 2005. ERK1/2 and MEK1/2 induced by Kaposi's sarcoma-associated herpesvirus (human herpesvirus 8 ) early during infection of target cells are essential for expression of viral genes and for establishment of infection. J Virol 79: 10308-10329.

Shin YK, Li Y, Liu Q, Anderson DH, Babiuk LA, Zhou Y 2007. SH3 binding motif 1 in influenza A virus NS1 protein is essential for PI3K/Akt signaling pathway activation. J Virol 82: 12730-12739.

Silva PN, Soares JA, Brasil BS, Nogueira SV, Andrade AA, de Magalhaes JC, Bonjardim MB, Ferreira PC, Kroon EG, Bruna-Romero O, Bonjardim CA 2006. Differential role played by the MEK/ ERK/EGR-1 pathway in orthopoxviruses vaccinia and cowpox biology. Biochem J 398: 83-95.

Soares JA, Leite FG, Andrade LG, Torres AA, de Sousa LP, Barcelos LS, Teixeira MM, Ferreira PC, Kroon EG, Souto-Padrón T, Bonjardim CA 2009. Activation of the PI3K/Akt pathway early during Vaccinia and Cowpox virus infections is required for both host survival and viral replication. J Virol 38: 6883-6899.

Srinivasan S, Wang F, Glavas S, Ott A, Hofmann F, Aktories K, Kalman D, Bourne HR 2003. Rac and Cdc42 play distinct roles in regulating $\mathrm{PI}(3,4,5) \mathrm{P}_{3}$ and polarity during neutrophil chemotaxis. J Cell Biol 160: 375-385.

Tan TT, Fang TL, Neo TL, Singh P, Zhang J, Zhou R, Koh C, Chan V, Lim SG, Chen WN 2008. Rac1 GTPase is activated by hepatitis B virus replication-involvement of HBX. Biochim Biophys Acta 1783: $360-374$
Teramoto H, Coso OA, Miyata H, Igishi T, Miki T, Gutkind JS 1996. Signaling from the small GTP-binding proteins Racl and Cdc42 to the c-Jun $\mathrm{N}$-terminal kinase/stress-activated protein kinase pathway. A role for mixed lineage kinase3/protein-tyrosine kinase 1, a novel member of mixed lineage kinase family. $J$ Biol Chem 271: 27225-27228.

Trindade GS, Emerson GL, Carroll DS, Kroon EG, Damon IK 2007. Brazilian Vaccinia viruses and their origins. Emerg Infect Dis 13: $965-972$.

Vorou RM, Papavassiliou VG, Pierroutsakos IN 2008. Cowpox virus infection: an emerging health threat. Curr Opin Infect Dis 21: $153-156$.

Wang JL, Zhang JL, Chen W, Xu XF, Gaos N, Fan DY, An J 2010. Roles of small GTPase Rac1 in the regulation of actin cytoskeleton during dengue virus infection. PLoS Negl Trop Dis 4: e809.

Wang SE, Shin I,Wu FY, Friedman DB, Arteaga CL 2006. HER2/ Neu (ErbB2) signaling to Rac1-Pak1 Is temporally and spatially modulated by transforming growth factor $\beta$. Cancer Res 66 : 9591-9600.

Wolf D, Witte V, Laffert B, Blume K, Stromer E, Trapp S, d'Aloja P, Schurmann A, Baur AS 2001. HIV-1 Nef associated PAK and PI3-kinases stimulate Akt-independent bad-phosphorylation to induce anti-apoptotic signals. Nat Med 7: 1217-1224.

Zamudio-Meza H, Castillo-Alvarez A, González-Bonila C, Meza I 2009. Cross-talk between Racl and Cdc42 GTPases regulates formation of filopodia required for dengue virus type- 2 entry into HMEC-1 cells. J Gen Virol 90: 2902-2911.

Zapata HJ, Nakatsugawa M, Moffat JF 2007. Varicella-zoster virus infection of human fibroblast cells activates the c-Jun N-terminal kinase pathway. J Virol 81: 977-990. 